\title{
ESTUDO DAS PROPRIEDADES FÍSICAS, MECÂNICAS E APLICAÇÃO DO CONCRETO LEVE COM A UTILIZAÇÃO DE AGREGADOS DE POLIESTIRENO EXPANDIDO - EPS
}

\section{STUDY OF PHYSICAL AND MECHANICAL CONCRETE AND APPLICATION OF LIGHT WITH POLYSTYRENE HOUSEHOLDS USING EXPANDED - EPS}

Bárbara Florrance de Melo Rocha, Filipe Bittencourt Figueiredo; Daniele Araujo Altran;

Universidade do Oeste Paulista-UNOESTE. Faculdade de Engenharia, Presidente Prudente, SP. Email:barbaraflorrance@hotmail.com

RESUMO - Este trabalho consiste no estudo das propriedades do concreto leve com a utilização de agregados de poliestireno expandido - EPS através de estudo teórico e metodologia experimental. Tem como objetivo analisar o concreto leve com a substituição do agregado graúdo pelo EPS, por não ser solúvel em água e não liberar substâncias ao meio ambiente, pode se tornar um agregado leve alternativo e uma solução para a redução de impactos ambientais. Os traços utilizados foram identificados em porcentagem de massa segundo a inclusão do EPS reciclado em substituição ao agregado graúdo. O piloto (0\%), traço $5 \%$, traço $10 \%$ e traço $15 \%$. Foram realizados 23 amostras de corpos de provas para cada traço. As amostras produzidas, 7 amostras foram submetidas à ensaios de absorção de água, índice de vazios e massas específicas do concreto endurecido. As 16 amostras restantes de cada traço foram subdivididas em 4 grupos de 4 corpos de provas para os ensaios de compressão mecânica a 7, 14, 21 e 28 dias. Os resultados mostraram que aos 28 dias, o traço de $5 \%$ atingiu resistência média de 20,53 MPa, e o traço de 10\% atingiu resistência média de 20,21 MPa. O traço de $15 \%$ obteve resistência média menor, de 18,45 MPa aos 28 dias.

Palavras-chave: Poliestireno Expandido; Concreto Leve.

ABSTRACT - This work is the study of light concrete properties with the use of expanded polystyrene aggregates - EPS through theoretical and experimental methodology. It aims to analyze the lightweight concrete with the replacement of coarse aggregate by EPS, not being soluble in water and does not release substances to the environment, can become an alternative lightweight aggregate and a solution for reducing environmental impacts. The strokes used were identified in mass percentage after the inclusion of EPS recycled to replace the

Recebido em: 05/08/2016 Revisado em: 26/08/2016 Aprovado em: 08/09/2016 coarse aggregate. The pilot (0\%) $5 \%$ trace, trace $10 \%$ and stroke by 15\%. 23 samples were made for evidence bodies for each trace. The produced samples, 7 samples were subjected to the water absorption test, voids and specific mass of hardened concrete. The remaining 16 
samples of each trace were subdivided into 4 groups of 4 test samples for mechanical compression tests 7, 14, 21 and 28 days. The results showed that at 28 days, the $5 \%$ average reached trait resistance 20.53 $\mathrm{MPa}$, and the $10 \%$ average reached trait resistance $20.21 \mathrm{MPa}$. The trace of $15 \%$ had lower average strength of $18.45 \mathrm{MPa}$ at 28 days.

Keywords: Expanded Polystyrene; Light Concrete. 


\section{INTRODUÇÃO}

O concreto leve pode ser utilizado em diversas áreas da construção civil. Entre os benefícios promovidos, está à diminuição da massa especifica proporcionada pelo uso de agregados leves que substituem total ou parcialmente os agregados convencionais. Entre suas vantagens ressalta-se a redução nos esforços na estrutura e na infraestrutura das edificações, a economia com fôrmas e cimbramentos, pela redução das solicitações, bem como a diminuição dos custos com transporte e montagem de construções préfabricadas, pela redução no peso dos materiais manuseados e aumento da produtividade (CATÓIA, 2012).

Entre os materiais utilizados como agregados leve, o Poliestireno Expandido (EPS) destaca-se por ser um material isolante térmico, leve devido sua baixa densidade, resistente, fácil de manusear e de baixo custo. Segundo Oliveira (2013), o EPS foi descoberto em 1949, é classificado como um polímero. A produção de EPS no mundo supera os 2,95 Milhões de toneladas ano e é utilizado em diversos setores de embalagens industriais, artigos de consumo, alimentício, agricultura e também na construção civil.

Neste trabalho foi executado um programa experimental com objetivo de estudar e analisar a substituição de diferentes proporções de substituições de agregado graúdo por pérolas de EPS, verificando as propriedades físicas e mecânicas dos traços realizados.

\section{METODOLOGIA}

Para a realização dos traços de concreto, foram utilizados os materiais descritos a seguir:

- Cimento: utilizado o cimento Portland II - F32 (CPII -Z- F32), composto para uso geral;

- $\quad$ Agregado Graúdo e Miúdo: Foram utilizados a brita tipo 1 e areia;

- $\quad$ Poliestireno Expandido - (EPS): Utilizou-se pérolas de EPS de granulometria de $5 \mathrm{~mm}$ fornecida pelo fabricante de densidade de $8 \mathrm{kgf} / \mathrm{m}^{3}$.

- Cola Branca (PVA): Para melhor aderência utiliza-se a cola branca de madeira extra adesivo de Poliacetato de Vinila (PVA) diluído na água de amassamento;

- Adesivo Chapix Quartzolit: empregou-se o adesivo em emulsão de polivinila (PVA) e aditivos especiais desenvolvidos para proporcionar melhor, diluído na água de amassamento.

Para as preparações dos concretos leves com a utilização de agregados de EPS o traço escolhido foi desenvolvido por Silva (1975), para atingir, após 28 dias de tempo de cura, a resistência mecânica mínima de 25 MPa, para concreto de uso geral. A partir deste, procurou-se verificar a influência da 
participação dos agregados de EPS quando inserida ao concreto na substituição parcial do agregado graúdo.

Utilizou-se o ensaio de granulometria para conhecer melhor as características e determinar a distribuição granulométrica do agregado miúdo (areia), graúdo (brita no1) e leve (EPS), seguindo a NBR NM 248/2003. Também foram realizados ensaios para a determinação das densidades do agregados através do método de volume conhecido.

Para os traços de 5, 10 e $15 \%$ de EPS, no início da mistura colocou-se na betoneira em movimento com parte da água, seguindo por $1 / 3$ da quantidade de cimento e o EPS. Foram adicionados o adesivo e a cola branca (PVA) diluídos em $1000 \mathrm{ml}$ da água de amassamento do concreto. Misturou-se por aproximadamente 3 minutos e foram adicionados parte da areia e a brita $\mathrm{n}$ 이. 0 restante do cimento, água, areia e brita, foram adicionados até que apresentassem consistência adequada para utilização como concreto. $\mathrm{O}$ concreto foi misturado durante 3 minutos, com volume de 44 litros de concreto por traço produzido. Após o preparo dos traços de concreto, foi realizado o ensaio de abatimento do tronco cone seguindo as recomendações da NBR NM 67/1998 e procedeu-se seguindo a NBR 5738/2015 para a moldagem dos corpos de provas e cura, para a realização dos ensaios para verificar as propriedades físicas e mecânicas do concreto.
Foram produzidos 92 corpos de prova no total, sendo que cada um possui $10 \mathrm{~cm}$ de diâmetro e $20 \mathrm{~cm}$ de altura.

Os corpos de provas foram capeados com enxofre derretido para o devido nivelamento da área submetida à compressão. Os ensaios de resistência mecânica à compressão foram realizados seguindo a NBR 5739/2007, no laboratório de engenharia civil da Universidade do Oeste Paulista - UNOESTE, em uma prensa com capacidade de carga de 20 toneladas.

Seguindo a NBR 9778/2005, foram realizados os ensaios de absorção de água por imersão, índice de vazios e massa especifica para cada traço de concreto produzido. Para a realização destes ensaios, foram utilizados 7 corpos de provas de cada traço, após 28 dias de tempo de cura.

\section{RESULTADOS}

Nos ensaios de granulometrias realizados, os agregados graúdos e miúdos mostraram-se com boa distribuição granulométrica, e o EPS com distribuição granulométrica uniforme de $5 \mathrm{~mm}$ identificados nos Gráficos 1, 2 e 3. 
Gráfico 1. Curva granulométrica da areia.

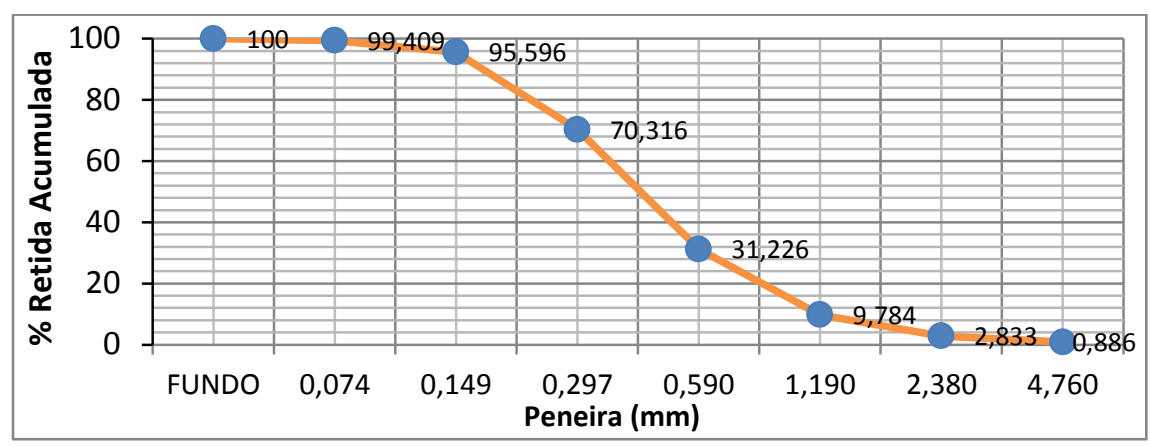

Gráfico 2. Curva granulométrica da brita 1.

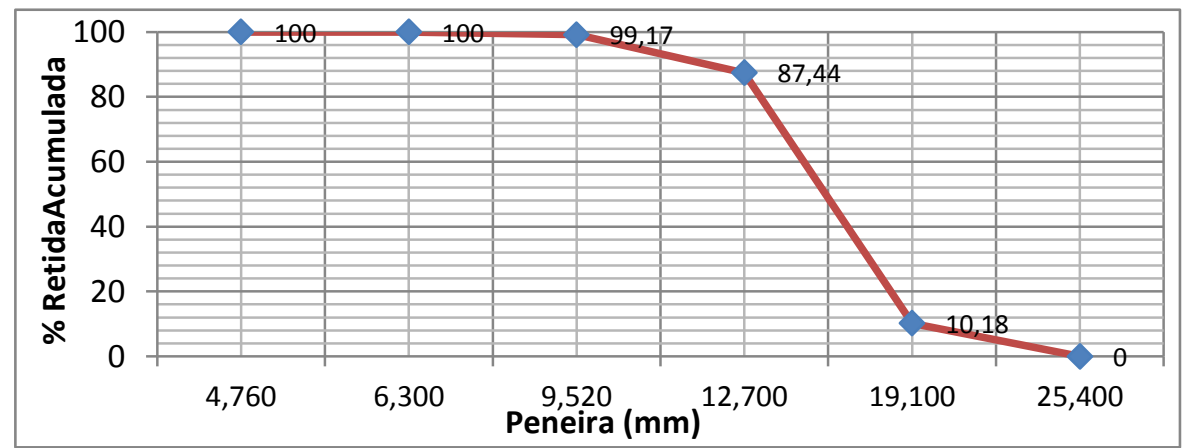

Gráfico 3. Curva granulométrica das pérolas de EPS.

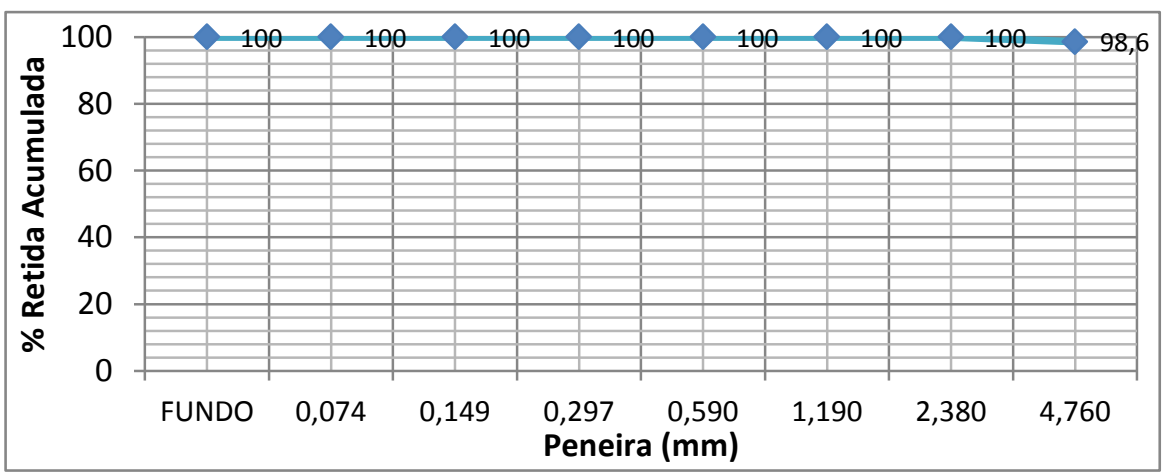

A seguir são apresentados os resultados

do ensaio de densidade dos agregados,

através da Tabela 1.

Tabela 1. Ensaio de densidade dos agregados.

\begin{tabular}{c|c}
\hline \multicolumn{2}{c}{ Método de volume conhecido } \\
\hline Agregado & Massa específica $\left(\mathbf{g} / \mathbf{c m}^{\mathbf{3}}\right)$ \\
\hline Graúdo - Brita 1 & 1,475 \\
\hline Miúdo - Areia & 1,643 \\
\hline Pérolas de EPS & 0,008 \\
\hline
\end{tabular}

No ensaio de abatimento do troncocone (Slump Test) foi possível analisar comparando com o valor do traço piloto que foi de $20,00 \mathrm{~cm}$, que os traços de $5 \%$ e $10 \%$ obtiveram maiores valores de abatimento, porém o traço de $15 \%$ obteve menor abatimento em relação ao piloto, influenciado pelas substituições em diferentes proporções do agregado leve de pérolas de EPS, cola branca de PVA e adesivo 
Chapix Quartzolit. Os resultados do ensaio

Tabela 2. Ensaio de abatimento do tronco-cone.

\begin{tabular}{c|c}
\hline \multicolumn{2}{c}{ Método de ensaio NBR NM 67: 1998} \\
\hline Amostras & Abatimento $(\mathbf{c m})$ \\
\hline Piloto $(0 \%)$ & 20,0 \\
\hline Traço (5\%) & 22,0 \\
\hline Traço (10\%) & 21,0 \\
\hline Traço (15\%) & 19,5 \\
\hline
\end{tabular}

Os ensaios de resistência à compressão

como também verificado seguindo a NBR

12644:2014, apresentaram uma diminuição nesta capacidade quando aumentada a são apresentados na Tabela 2.

substituição do agregado graúdo por agregado leve (Gráfico 1), e também o aumento das proporções de cola branca de PVA e adesivo Chapix Quartzolit. Observa-se que nos traços que quanto maior a porcentagem substituída menor foram os resultados.

Gráfico 4. Ensaio de resistência mecânica no módulo de compressão (em MPa) dos corpos de prova fabricados com 0, 5, 10 e 15\% de EPS e curados a 7, 14, 21 e 28 dias.

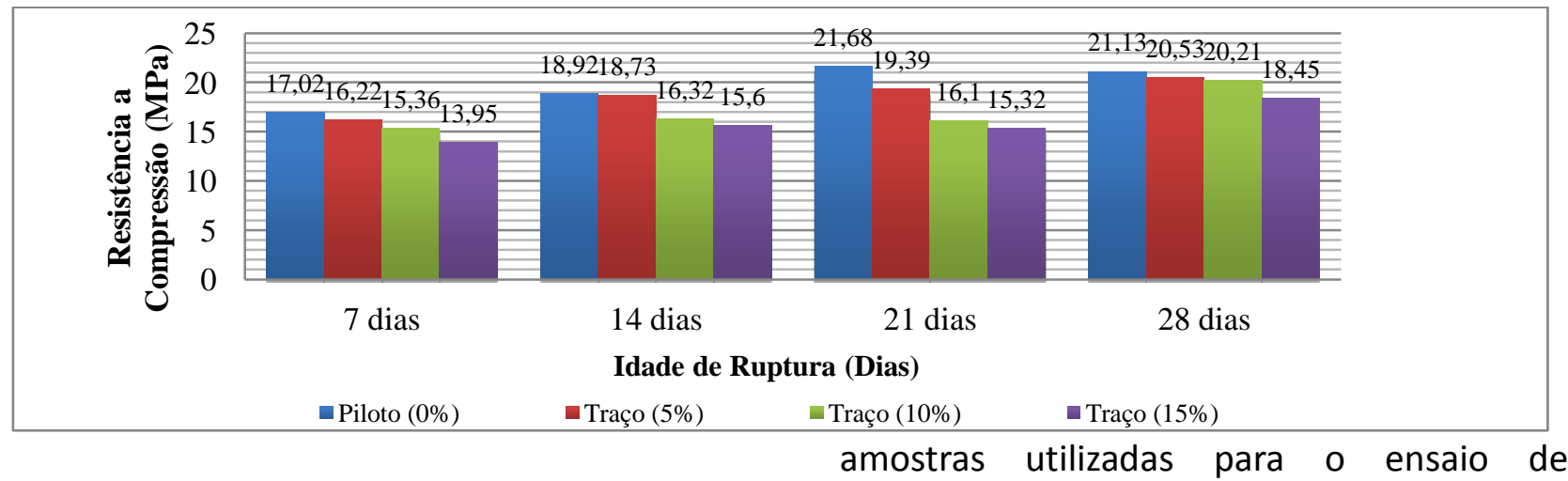

Entre as amostras utilizadas para o resistência à compressão e a redução, ensaio de resistência a compressão, foram apresentados na Tabela 3. verificadas as médias das massas das

Tabela 3. Médias das massas das amostras utilizadas para o ensaio de resistência à compressão.

\begin{tabular}{c|c|c|c}
\hline Amostras & $\begin{array}{c}\text { Massa média das amos- } \\
\text { tras (kg) }\end{array}$ & $\begin{array}{c}\text { Massa média em relação } \\
\text { ao piloto (\%) }\end{array}$ & $\begin{array}{c}\text { Redução da massa média } \\
\text { em relação ao piloto (\%) }\end{array}$ \\
\hline Piloto (0\%) & 3,836 & $100,00 \%$ & $0,00 \%$ \\
\hline Traço (5\%) & 3,727 & $97,18 \%$ & $2,82 \%$ \\
\hline Traço (10\%) & 3,574 & $93,18 \%$ & $6,82 \%$ \\
\hline Traço (15\%) & 3,499 & $91,23 \%$ & $8,77 \%$ \\
\hline
\end{tabular}

São apresentados a seguir (Tabela 4), os

Constatou-se que a amostra referente ao resultados obtidos do ensaio de absorção e índice de vazios das amostras de concreto no estado endurecido. traço piloto apresentou-se maior. Os traços de $5 \%, 10 \%$ e $15 \%$ apresentaram menores valores. 
Tabela 4. Ensaios de absorção de água e índice de vazios das amostras.

Método de ensaio NBR 9778:2005

\begin{tabular}{c|c|c}
\hline Amostras & Porcentagem de absorção (\%) & Porcentagem de índices de vazios (\%) \\
\hline Piloto (0\%) & $4,63 \%$ & $10,16 \%$ \\
\hline Traço (5\%) & $3,88 \%$ & $8,37 \%$ \\
\hline Traço (10\%) & $1,34 \%$ & $2,61 \%$ \\
\hline Traço (15\%) & $4,52 \%$ & $9,10 \%$ \\
\hline
\end{tabular}

presença de EPS no concreto (Gráfico 2), foi

O resultado das massas especifica possível verificar redução de seus valores em obtidas a seguir mostram que com a relação ao traço piloto.

Gráfico 5. Comparação das massas específicas em g/ $\mathrm{cm}^{3}$.

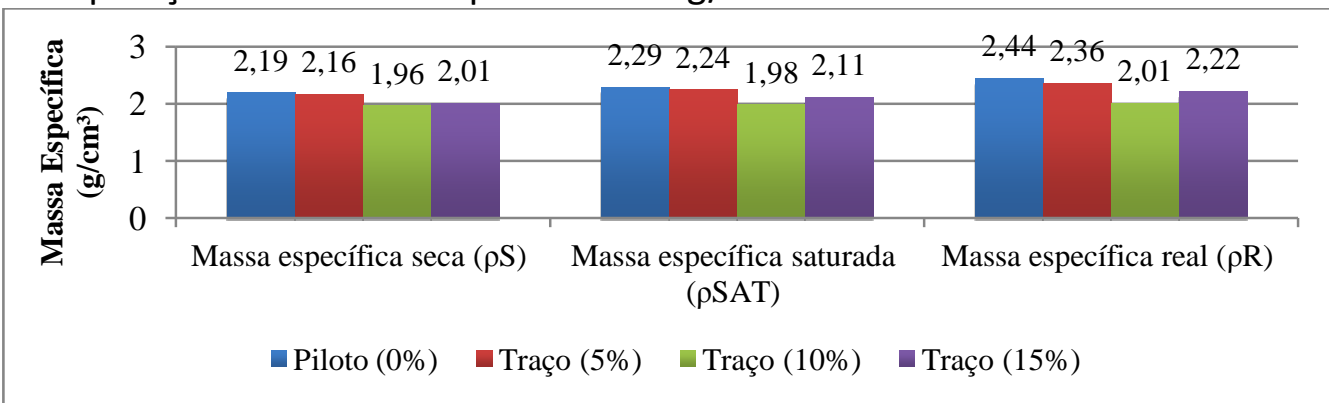

\section{DISCUSSÃO}

Existem muitos aspectos que ainda podem ser estudados na utilização de EPS no concreto e aditivos, portanto, sugere-se a procura por um aditivo que substitua a cola branca (PVA) e que ajude na mistura do EPS ao concreto, sem tanta perda de resistência. Indica-se o estudo da microestrutura das partículas do concreto produzido por EPS, e o controle do fator de água e cimento do concreto, que é determinante para a sua resistência, levando em consideração que as pérolas de EPS possuem uma microestrutura, que contem mínima absorção de água.

\section{CONCLUSÃO}

Com base nos experimento e nos resultados dos ensaios realizados, conclui-se que a resistência à compressão, trabalhabilidade e densidade, são as propriedades que mais sofrem alteração com - emprego do EPS. Comparando-se os ensaios de Slump Test, houve variações nos valores de abatimento devido à influência das diferentes proporções usadas de EPS, cola branca e adesivo, fluido, contudo em condições para aplicação prática.

O trabalho se apropriou de metodologia experimental, onde a resistência à compressão do traço usado como referência obteve resultado de 21,13 $\mathrm{MPa}$ aos 28 dias. Portanto possibilitando influencia de não consideradas as quantidades de umidade da areia utilizada nos traços produzidos. A substituição do agregado graúdo EPS, mostrou-se viável para o 
emprego de concreto que necessite de resistência de $20 \mathrm{MPa}$, para o traço de $5 \%$ atingindo resistência média de 20,53 MPa, e o traço de $10 \%$ atingindo resistência média de 20,21 MPa. O traço de 15\% obteve resistência média menor, de 18,45 $\mathrm{MPa}$ aos 28 dias. O comportamento na ruptura do concreto com EPS mostrou-se diferente do traço piloto. No piloto, as falhas mostraramse unidirecional e concentrada. Os traços com EPS houve o surgimento de fissuras ao redor das pérolas, com aumento de porosidade evidente, descontinuas, mostrando a falta de rigidez do EPS.

Houve a redução da massa especifica do concreto, possibilitando a diminuição do peso do concreto, consequentemente contribuindo para a redução do peso próprio estrutural e para economia no custo final da obra. O emprego da cola branca de madeira (PVA) contribuiu para valores inferiores de resistência, alteração na porosidade e aumento da absorção de água, principalmente para o traço de $15 \%$, onde se utilizou uma maior quantidade em relação aos outros traços. Isso acontece devido a característica da cola, que após o tempo de secagem, torna-se um material elástico, ocupando espaços na pasta de cimento, se comportando também como vazios.

\section{REFERÊNCIAS}

ABNT NBR NM 248. Agregados Determinação da composição granulométrica. Rio De Janeiro: ABNT, 2003.

ABNT NBR 12644. Concreto leve celular estrutural - Determinação da densidade de massa aparente no estado fresco. Rio de Janeiro: ABNT, 2014.

ABNT NBR 5738. Concreto: procedimento para moldagem e cura de corpos de prova, para realizar os ensaios de resistência à compressão. Rio de Janeiro: ABNT, 2015.

ABNT NBR 5739. Concreto: ensaio de compressão de corpos-de-prova cilíndricos. Rio de Janeiro: ABNT, 2007.

ABNT NBR 9778. Argamassa e concreto endurecido - Determinação da absorção de água, índice de vazios e massa específica. Rio de Janeiro: ABNT, 2005.

ABNT NBR NM 67. Concreto - Determinação da consistência pelo abatimento do tronco de cone. Rio de Janeiro: ABNT, 1998.

CATÓIA, T. Concreto Ultraleve ${ }^{\circledR}$ estrutural com pérolas de EPS: caracterização do material e estudo de sua aplicação em lajes. 2012. Tese (Doutorado) - Escola de Engenharia de São Carlos, São Carlos, 2012.

OLIVEIRA, Lívia. S. Reaproveitamento de resíduos de poliestireno expandido (ISOPOR) em compósitos cimentícios. 2013. Programa de Pós-Graduação em Engenharia Mecânica, Universidade Federal de São João Del-Rei, 2013.

SILVA, G.R. Manual de traços de concreto. São Paulo: Nobel, 1975. 113p. 